\title{
The effects of selection systems and implicit theories on individual effort
}

\author{
Keita SUZUKI1),*, Tomoya YOSHINO2),**, Yukiko MURAMOTO1) \\ 1)Graduate School of Humanities and Sociology, The University of Tokyo \\ 2)Faculty of Letters, The University of Tokyo
}

\begin{abstract}
Although it is well known that implicit theories (beliefs regarding the malleability of human attributes) affect one's motivation, less is known about how these effects manifest themselves in certain educational environments. This study investigated how implicit theories moderate the effects of selection systems, which are prevalent in educational settings, on individual effort. The results indicated that when entity theorists (people who think ability is fixed) who performed relatively well received negative feedback and were not selected, they exerted less effort compared with incremental theorists (people who think ability is malleable). The negative effects of selection systems on motivation might be amplified among entity theorists when they are faced with an undefeatable rival.
\end{abstract}

Key Words: implicit theories, selection system, goal orientation, achievement motivation

\section{Introduction}

In the context of achievement, it is well known that belief in the malleability of human attributes (implicit theories: Dweck, 1986) is a significant factor that affects one's motivation. Entity theorists, people who believe that ability is fixed, tend to show a pattern of helplessness when confronting difficulty, relative to incremental theorists, people who believe that ability is malleable (Dweck, 1986). Many researchers have investigated the effect of holding a specific theory in educational settings and have suggested some favorable aspects of incremental theory (e.g., Blackwell, Trzesniewski, \& Dweck, 2007). The effect of implicit theories on motivation under a certain educational environment, however, has not been examined in any detail. The present study focuses on a selection system (e.g., entrance examination) as a considerable environmental factor, and examines how incremental and entity theorists get motivated or demotivated.

\section{Implicit theories and goal orientation}

Incremental and entity theorists are motivated to pursue different goals (Dweck, 1986). Incremental theorists tend to hold learning goals, which motivate individuals to improve themselves, and entity theorists tend to hold performance goals, which motivate individuals to gain positive evaluations of their competence and confirm their ability. When people hold learning goals, they take on mastery-oriented behavior, such as seeking out difficult tasks (Dweck, 1986). People holding performance goals are also mastery-oriented in their behavior when they are confident in their competence; however, when they are not confident, they tend show more helpless behavior (Dweck, 1986).

\section{The effect of implicit theories in educational settings}

The positive effects of holding incremental theory in educational settings have been reported in many studies. Blackwell et al. (2007) conducted a survey that revealed that junior high school students with incremental theory

\footnotetext{
* Corresponding Author e-mail: atiek328ikuzus@yahoo.co.jp

** Current affiliation: MUFG Bank, Ltd.

Online Appendix: https://doi.org/10.2130/jjesp.1912
} 
Suzuki, Yoshino \& Muramoto: The effects of selection systems and implicit theories on individual effort

show mastery-oriented patterns, such as not avoiding difficult tasks and, consequently, receive higher grades. These effects are also observed in interventional studies (e.g., Paunesku et al., 2015).

However, the way in which implicit theories interact with various educational environments is not investigated enough. Considering the characteristics of implicit theories, the same environment may exert different impacts on the motivation of incremental theorists and that of entity theorists, respectively. Here, we focused on a selection system, which is a prevalent and significant factor in education (Suzuki, 2014), and investigated how implicit theories moderate the effect of the system on motivation.

\section{Selection system in educational settings}

In the present research, we focused on a selection system to choose a person who has high ability or desirable attributes, which makes it visible who has the desired characteristics and who does not (e.g., Gilliland, 1993). For example, being selected as a student through entrance exams means that you are recognized to have the desired characteristics, and other people will clearly acknowledge that. If so, a selection system could strongly evoke performance goals in an individual. At the same time, however, the selection system could evoke feelings of helplessness in an individual who does not have confidence in being selected. This pattern could be more prevalent among entity theorists, who have a stronger tendency to evoke performance goals than incremental theorists do. The selection system would strengthen the tendency of entity theorists to seek for positive evaluations and confirmation of their ability, and thus it would especially demotivate them when they think they fail; this is our main hypothesis. On the other hand, incremental theorists would be less affected by the selection system because it is more important for them to improve themselves than to get positive evaluations or confirm of their ability.

\section{Overview of this research and the hypothesis}

In the present research, we assumed that the amount of effort individuals make would reflect their motivation and that a selection system would lead individuals to evoke performance goals. We then hypothesized that a selection system would lead individuals, especially entity theorists, to reduce their amount of effort and become helpless when they think that they may not be able to pass the selection.

To test our hypothesis, we conducted a laboratory experiment. Two participants in the same room were asked to engage in a drawing task individually several times. The time they spent practicing during the interval was measured as an index of the amount of effort. Half of the participants were informed that only the better of the two drawings would be used for the research (selection condition), and the other half did not receive this information (non-selection condition). After their first trial, participants were told that their performance was worse than that of their partners. Our working hypothesis was as follows:

Hypothesis: After receiving negative feedback about their performance so far, entity theorists would make less effort in the selection condition than those in the non-selection condition, whereas there would be no effect of selection among incremental theorists.

\section{Method}

\section{Participants}

Sixty-two graduate and undergraduate Japanese students (40 males, 22 females, $M_{\text {Age }}=21.6, M_{S D}=1.24$ ) participated in the experiment. They participated in pairs; however, the pairs did not know each other. During the experiment, they were separated by a partition. The pairs of participants were randomly assigned to either the selection condition or the non-selection condition. Participants were asked to engage in a mirror drawing task several times; their scores and the time they spent practicing during the interval were measured (details in Appendix 1).

\section{Procedure}

Measuring implicit theories. Before the task began, participants were asked to fill out a questionnaire comprising three question items that measure implicit theories (Hong, Chiu, Dweck, Lin, \& Wan, 1999) with a slight modification. We measured the general belief about human ability, rather than the participant's specific ability (e.g., "People have a certain amount of intelligence, and you really cannot do much to change it”). The Japanese translation was based on Oikawa (2005). A higher score indicated an endorsement of entity theory.

Explanation of the experiment. Next, participants were informed of the whole task of the experiment. They were first told that the experiment was to test college students' 
perceptions. Then they were told about the rules and content of the mirror drawing task and the criteria used to calculate the scores. In addition, they were told that they would perform the same kind of task twice, and after each task, they would receive feedback regarding their scores and those of their partner.

To manipulate the existence of the selection, participants in the selection condition received the following information: "According to previous research, people who have good somatic sensation can achieve good scores in the mirror drawing test. In this experiment, we are thinking of using the data from the person who has better somatic sensation. So, we are going to use the better score between the two of you." Participants in the non-selection condition did not receive that information.

Practice, first trial, and mid-task questionnaire. After the instructions, participants went through a practice trial to ensure that they understood the rules of the task correctly. Then, participants went through the first test trial. After the trial, the experimenter collected the papers and calculated the scores while the participants answered a mid-task questionnaire. The questionnaire included eight items regarding goals set by participants during the first trial. The items were based on the Japanese version of achievement goal scale (Elliot \& Church, 1997; translated by Mitsunami, 2010) but were modified to capture their specific goals for this experimental setting. As we assumed that the selection system would motivate participants to pursue performance goals, the average score of three items indicating the extent to which they evoked performanceapproach goals were used for the manipulation check. The questionnaire items are listed in Appendix 2 with the results of factor analysis and descriptive statistics.

Feedback. The participants received feedback regarding their and their partner's scores. Since our purpose was to focus on the pattern after experiencing failure, participants received false feedback. Specifically, participants in the selection condition were told, "Your score was X points; your partner's score was Y points. Since your partner's score was higher, we will use the partner's data for subsequent analyses this time." Participants in the non-selection condition were told, "Your score was X points; your partner's score was Y points.” In both conditions, $\mathrm{X}$ points was the true score of the participant, while $\mathrm{Y}$ points was not the partner's real score but was manipulated to be higher than the participant's score. Participants received this feedback on paper so that they would not be informed what kind of feedback their partner received.

Interval. Four minutes were given as an interval. Participants could practice if they wanted to do so. The time participants spent practicing was measured as the dependent variable.

Second trial and post-task questionnaire. After the interval, participants went through the second trial with the same procedure as the first trial. Then they filled out the post-task questionnaire, and the entire task was completed. However, there were no significant results to report regarding the post-task questionnaire, so we omitted them from this paper.

\section{Results}

\section{Descriptive statistics}

All of the analyses were conducted using the HAD (Shimizu, 2016). Descriptive statistics are displayed in Table 1 . The reliability of items measuring implicit theories $(\alpha=.807)$ and performance-approach goals ( $\alpha=.851$ ) was high enough, so we used the mean scores of those items.

\section{Manipulation check}

The one-way ANOVA revealed that participants in the selection condition tended to pursue performance-approach goals $(M=2.72 ; S D=.68)$ more strongly than those in the

Table 1 Descriptive statistics of main variables

\begin{tabular}{|c|c|c|c|c|c|c|}
\hline & \multicolumn{2}{|c|}{$\begin{array}{l}\text { selection } \\
\text { condition } \\
(N=31)\end{array}$} & \multicolumn{2}{|c|}{$\begin{array}{c}\text { non-selection } \\
\text { condition } \\
(N=31)\end{array}$} & \multicolumn{2}{|c|}{$\begin{array}{c}\text { ALL } \\
(N=62)\end{array}$} \\
\hline & $M$ & $S D$ & $M$ & $S D$ & $M$ & $S D$ \\
\hline implicit theories & 3.11 & 1.02 & 2.69 & 0.83 & 2.90 & 0.94 \\
\hline practice time & 112.55 & 81.01 & 151.16 & 61.16 & 131.85 & 73.80 \\
\hline
\end{tabular}


Suzuki, Yoshino \& Muramoto: The effects of selection systems and implicit theories on individual effort

non-selection condition $(M=2.29 ; S D=.97)$ during the first trial $(F(1,60)=4.12, p=.046)$. We concluded that the manipulation of the selection system had succeeded and moved on to the hypothesis testing. ${ }^{1), 2)}$

\section{Hypothesis testing}

Since the practice time was limited to 240 seconds, we conducted a tobit regression analysis (upper $=240$ ). The dependent variable was the practice time, and independent variables were implicit theories (IT), selection condition ( $0=$ non-selection, $1=$ selection), and their interactions (Table 2, Model 1). Results revealed that the main effect of the selection condition was marginally significant $(\beta=-223$, $p=.080$ ), which indicates that participants in the selection condition practiced less during the interval. However, the interactions did not reach significance $(\beta=.-100, p=.409)$, which indicates that the hypothesis was not supported.

\section{Additional analyses}

We considered the possibility that the bogus feedback that participant's score was lower than their partner's score had a different impact depending on their actual performance of the first task. Therefore, we added the participant's score on the first task (Score 1) and its interactions with implicit theories and selection condition to Model 1 and conducted a tobit regression analysis (upper 240, Table 2, Model 2).
The results revealed that the three-way interaction was significant $(\beta=-.193, p=.037)$. The simple interaction analysis revealed that among participants whose scores were relatively lower $(-1 S D)$, the interaction IT $\times$ selection ( $\beta=.152, p=.510$ ) was not significant; however, among highscoring participants $(+1 S D)$, the interaction IT $\times$ selection was significant $(\beta=-.529, p=.014)$. As shown in Figure 1 , a simple slope analysis revealed that the main effect of the selection ( $\beta=.152, p=.449)$ was not significant among incremental theorists $(-1 S D)$; however, it was significant $(\beta=-.609, p=.018)$ among entity theorists $(+1 S D)$, which indicates that entity theorists who received relatively high scores in the selection condition made less effort. The main effect of implicit theories was significant $(\beta=-.775, p<.001)$ in selection condition, whereas it was not significant in nonselection condition ( $\beta=-.021, p=.927)$, which indicates that in selection condition, entity theorists made less effort compared to incremental theorists.

\section{Discussion}

Our purpose was to investigate how implicit theories moderate the effect of selection system on motivation. We predicted that entity theorists will make less effort when they think they might not be selected. The results partly supported the hypothesis, indicating that individuals who received negative feedback in a selection situation tended to

Table 2 The effects of selection condition, implicit theories (IT), the first trial score (Score 1), and interactions on practice time

\begin{tabular}{lcc}
\hline & Model 1 & Model 2 \\
\hline Selection $(0=$ non-selection, 1=selection) & $-.223^{\dagger}$ & $-.208^{\dagger}$ \\
Implicit Theories (IT) & -.136 & $-.185^{\dagger}$ \\
First Trial Score (Score 1) & & $-.209^{\dagger}$ \\
Selection $\times$ IT & -.100 & -.131 \\
IT $\times$ Score 1 & & $-.169^{\dagger}$ \\
Selection $\times$ Score 1 & & -.020 \\
Selection $\times$ IT $\times$ Score 1 & & $-.193^{*}$ \\
\hline$R^{2}$ & $.097^{\dagger}$ & $.296^{* *}$ \\
\hline
\end{tabular}

$* * p<.01, * p<.05,+p<.10$

1) As for the other two subscales (i.e., performance-avoidance goals and mastery goals), there were no significant difference between the selection condition and the non-selection condition $(F(1,60) \leq 0.453$, n.s.).

2) None of the three subscales of achievement goals were significantly correlated with the implicit theories $(r \mathrm{~s} \leq 0.160, n . s$.). This is a reasonable result considering that our scale was to measure specific goals set by participants for this experimental setting, rather than their orientations in general. 
Low Score $(-1 S D)$

High Score $(+1 S D)$

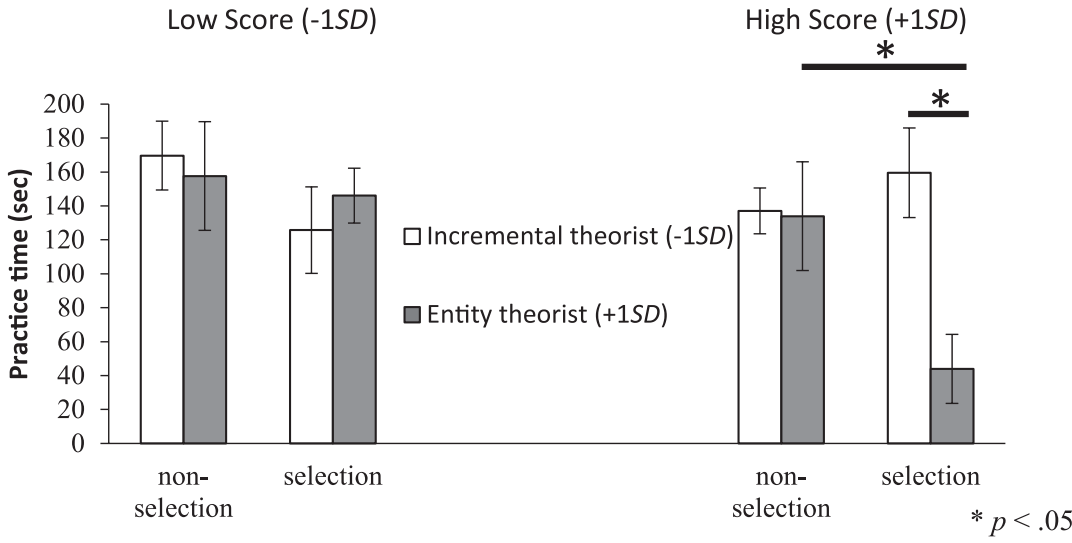

Figure 1 Effects of selection conditions, implicit theories, and the first trial score on practice time Note. The error bar reflects standard error.

make less effort. This tendency was especially true among entity theorists in the selection situation who performed well on the first task but were told that their score was lower than their partner's score. On the other hand, when their performance was not very good, there was no difference in the amount of effort made by entity theorists and incremental theorists for the subsequent task.

These results suggest that entity theorists in a selection situation expend less effort when they see others demonstrate an appreciably high level of competence. The fact that they cannot surpass others even though they also have a certain level of competence might lead entity theorists to a feeling of helplessness. However, the results also suggest that entity theorists will put in effort just as incremental theorists do when they are not in a selection situation. The negative effect of the undefeatable rival may have a considerable impact on entity theorists only when they are involved in a selection system.

What kind of feature of selection system causes such effects? In our experiment, participants in both conditions received the same feedback of their and their partner's scores. Only the difference between the two conditions was whether the instruction that the better data was going to be analyzed was provided or not. This means that being evaluated or compared with others is not the cause of the difference in the amount of effort among participants. Rather, it should be noted that the selection system differentiates individuals who are chosen from those who are not chosen. This visualization of having or not having the desired property may affect the motivation of entity theorists and their amount of effort.

We should point out that, in our experiment, the partner was the same person throughout, and the participants had no choice to change their partners. Suzuki \& Muramoto (2017) have indicated that entity theorists tend to seek an environment that suits them and will try to change the environment if it does not suit them. When entity theorists realize that they cannot change an environment that is unsuited to them, it evokes a feeling of helplessness. The entity theorists in our experiment might have perceived the environment as unchangeable, where they did not have an opportunity to compete with another partner and defeat him/her. If so, this could be one of the reasons why only the entity theorists who received relatively high scores in the first trial reduced their effort after the feedback.

The results of the present research suggest that the relationship between individuals' motivation and implicit theories is more complicated than has been discussed in previous research. Further research is needed with a more sophisticated method to manipulate a selection system, in order to clarify the difference in the psychological impacts that a selection system imposes on entity and incremental theorists.

\section{References}

Blackwell, L. S., Trzesniewski, K. H., \& Dweck, C. S. (2007). Implicit theories of intelligence predict achievement across an adolescent transition: A longitudinal study 
Suzuki, Yoshino \& Muramoto: The effects of selection systems and implicit theories on individual effort

and an intervention. Child Development, 78, 246-263.

Dweck, C. S. (1986). Motivational processes affecting learning. The American Psychologist, 41, 1040-1048.

Elliot, A. J., \& Church, M. A. (1997). A hierarchical model of approach and avoidance achievement motivation. Journal of Personality and Social Psychology, 72, 218232.

Gilliland, S. W. (1993). The perceived fairness of selection systems: An organizational justice perspective. The Academy of Management Review, 18, 694-734.

Hong, Y., Chiu, C., Dweck, C. S., Lin, D., \& Wan, W. (1999). Implicit theories, attributions, and coping: A meaning system approach. Journal of Personality and Social Psychology, 77, 588-599.

Mitsunami, M. (2010). Influence of achievement motive and goal orientation on learning behavior: Difference in cognitive strategies. Japanese Journal of Educational Psychology, 58, 348-360. (In Japanese with English Abstract)

Oikawa, M. (2005). Participants' theories of intelligence and pursuit of nonconscious goals. Japanese Journal of Educational Psychology, 53, 14-25. (In Japanese with
English abstract)

Paunesku, D., Walton, G. M., Romero, C., Smith, E. N., Yeager, D. S., and Dweck, C. S. (2015). Mind-set interventions are a scalable treatment for academic underachievement. Psychological Science, 26, 784-793.

Shimizu, H. (2016). An introduction to the statistical free software HAD: Suggestions to improve teaching, learning and practice data analysis. Journal of Media, Information and Communication, 1, 59-73. (In Japanese with English abstract)

Suzuki, M. (2014). Relation between views of competitions on university entrance examinations, motivation for learning, anxiety, and learning dispositions. Japanese Journal of Educational Psychology, 62, 226-239. (In Japanese with English abstract)

Suzuki, K., \& Muramoto, T. (2017). Is increment theorist more adaptive than entity theorist in situation with multiple options?: Focusing on sensitivity to opportunity cost. Paper presented at 12th biennial Asian Association of Social Psychology (Auckland, New Zealand). 